\title{
Publisher Correction to: A Paradifferential Approach for Well-Posedness of the Muskat Problem
}

\author{
Huy Q. Nguyen \& Benoît Pausader \\ Correction to: Arch. Rational Mech. Anal. \\ https://doi.org/10.1007/s00205-020-01494-7
}

Due to typesetting mistakes, several errors have been introduced.

In section 1.3, first paragraph, last line, the last sentence should read: "We also refer to [26, 27, 34, 42] for results on maximum principle and stability."

In Appendix A, last equation, last two lines, the factor $\mathrm{h}$ should have been deleted.

At the beginning of heading 4.2.2 "A priori" should have been deleted.

The original article has been corrected.

Publisher's Note Springer Nature remains neutral with regard to jurisdictional claims in published maps and institutional affiliations.

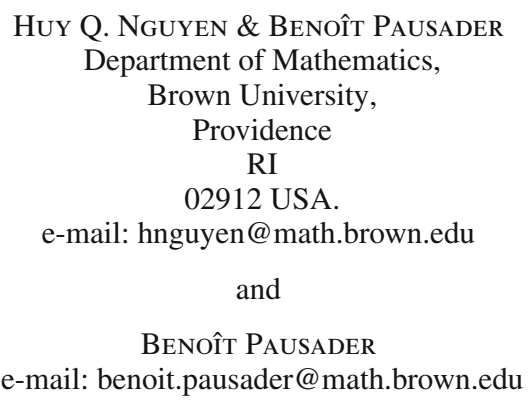

Published online March 17, 2020

(C) Springer-Verlag GmbH Germany, part of Springer Nature (2020)

The original article can be found online at https://doi.org/10.1007/s00205-020-01494-7. 